\section{artelogie}

\section{Artelogie}

Recherche sur les arts, le patrimoine et la littérature de l'Amérique latine

\section{$13 \mid 2019$}

Violeta Parra: authenticité, primitivisme et processus d'exotisme chez les artistes latino-américains.

\title{
Violeta Parra, después de vivir un siglo, Consejo Nacional de la Cultura y las Artes de Chile (CNCA), 2017, Santiago: CNCA.
}

Javiera Blanco

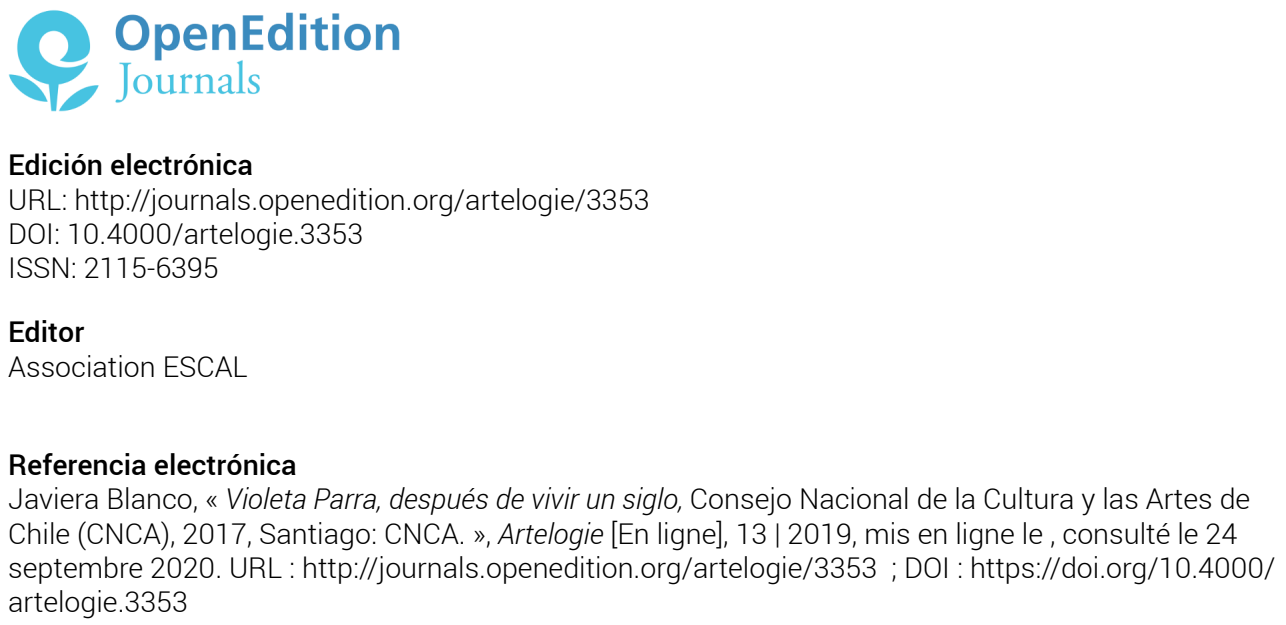

Este documento fue generado automáticamente el 24 septembre 2020.

Association ESCAL 


\title{
Violeta Parra, después de vivir un siglo, Consejo Nacional de la Cultura y las Artes de Chile (CNCA), 2017, Santiago: CNCA.
}

\author{
Javiera Blanco
}

1 El libro Violeta Parra, después de vivir un siglo es una publicación especial de la Revista observatorio Culturali, realizada en el marco de la conmemoración del centenario de Violeta Parra, una edición que ofrece una mirada crítica y reflexiva desde diversas disciplinas, resaltando los hallazgos recientemente descubiertos sobre su vida y obra. Además, posee la singularidad de ser la única publicación desde el Estado, en la cual se reconoce la deuda histórica y el compromiso irrenunciable de divulgar y profundizar en el legado de Violeta. Esta publicación nos entrega un excelente epítome de lo que sabemos sobre la cantautora a cien años de su nacimiento, relevando, por fin, lo que su creación artística y vida nos ha significado. Su revolucionaria lucidez, generosa creatividad e irrepetible talento hacen que en diferentes párrafos de este libro se le denomine la profetiza de Chile, la estrella mayor que el país ha tenido o quien estaba destinada a escribir la gran novela de Chile.

El libro reúne ocho artículos y cuatro fragmentos de académicos y académicas que repensaron y rememoraron la figura y obra de Violeta Parra. Una interesante manera de comprobar el prolijo trabajo realizado por cada uno y una es que, pese a la especificidad de las áreas de análisis, se evidencian líneas transversales que se funden en la idea de que Violeta descifró y comprendió en altos niveles los mensajes de la sabiduría popular u originaria, ejercicio sólo posible de lograr a través del recorrido que realizó por la geografía humana y espiritual del territorio chileno.

El orden de los artículos no es casualidad y la publicación comienza con el texto de Bernardo Subercaseaux, quien entrega información histórica del contexto político y social en el que vivió Violeta y cómo esto fue determinante para su creación y propuesta artística. El autor distingue cuatro etapas en su vida, en donde destacan: el 
proceso de aprendizaje no institucionalizado en su comunidad campesina, el traslado a Santiago, los viajes de investigación y recopilación y sus últimos años de vida, que se caracterizan por la intensa labor creativa. Un aporte fundamental del escrito es la idea de Violeta como un puente entre las costumbres y el folclor en sus fuentes originales, transformándolos y resignificándolos en resonancia con los tiempos que le tocó vivir.

Por otra parte, Sonia Montecino aborda una de las temáticas menos exploradas en torno a la obra de Violeta, siendo una de las mayores contribuciones de este libro. Montecino analiza las construcciones de género presentes en la obra poética de Violeta, aproximándola a una de las discusiones más actuales en la sociedad chilena. Para la autora, Violeta es una representante del "feminismo popular", es decir, aquel que se inicia desde la experiencia y la propia reflexión de las vivencias femeninas al interior de una estructura de subordinaciones y mandatos de género. Violeta es una mujer que nace en el Chile de principios del siglo XX, en un universo campesino-mestizo que le significó ser portadora de una doble desventaja: de género y social. No obstante, sólo una mente lúcida como la de ella fue capaz de gestar una clara conciencia de los principales nudos que impedían a las mujeres ser autónomas, libres y creadoras.

El tercer texto es un trabajo periodístico realizado por Marisol García, el cual busca introducirnos en el pensamiento de la cantautora a través del análisis de sus propias palabras. La autora postula que Violeta nunca se refirió a sí misma como "artista", sino que se consideraba una recopiladora, aprendiz y divulgadora. Esta idea es fundamental para entender su decisión de servir a la continuidad de la tradición popular y de no centrarse en su expresión individual. En el artículo se deja en claro que Violeta entendía su obra como el resultado de un diálogo e intercambio con muchas otras voces, mezcladas en el tiempo y origen, y por ello que el canto de todos es su propio canto, por encima el coro de todos, por debajo su propia voz.

Maximiliano Salinas pone énfasis en el minucioso trabajo desarrollado por Violeta al recoger la literatura oral campesina e indígena, estableciendo un nexo entre el texto que lo antecede y el que lo sigue. Salinas expone que Violeta nos dejó la iluminación del tiempo mestizo de su época, siendo capaz de recrearlo a través de su personal creatividad artística, y con ciertos horizontes del sentido del tiempo y del amor que serán nutridos por estas tradiciones místicas y poéticas de los Andes australes y de la península ibérica.

7 Uno de los mayores hallazgos del libro está presente en los textos de Paula Miranda y Elisa Loncon, ambas contribuyen en esta publicación con una temática que cambia rotundamente la perspectiva con la que se había analizado hasta ahora, la obra y vida de Violeta Parra. El gran hallazgo de las autoras fue encontrar evidencia empírica de que Violeta compartió íntimamente con el pueblo mapuche. Sus escritos nos revelan que la cantautora internalizó las características de sus cantos, siendo sus canciones analogías y generando constantes vínculos con los sonidos y sensaciones de la naturaleza, pero lo más importante, es que comprendió la cosmovisión mapuche y la responsabilidad social presente en ello, visible en su ímpetu por querer cambiar el mundo por uno mejor.

El análisis de la obra visual de Violeta Parra es una temática casi inexplorada, principalmente, porque siempre se le asocia a su música y su arte plástico ha sido categorizado por la crítica especializada como "naif", desplazándolo a un segundo plano. Felipe Quijada en su texto aborda esta temática como una defensa extraordinaria de quien comprende el rubro de las artes plásticas y el pensamiento de Violeta. Quijada 
vincula ideas mencionadas anteriormente, como que las fuentes populares no son ilustraciones de una alteridad en la creación de Violeta, releva su relación con lo mapuche, su originalidad y, por supuesto, su carácter atemporal. El autor establece que esta última característica transformó a Violeta en una trashumante que vivió en un exilio permanente, no de lugar, sino de tiempo, de quien constantemente se confirma su contemporaneidad con el presente, y porque no decirlo, con el presente de mañana.

El libro finaliza con el texto de Gastón Soublette, quien trabajó y compartió íntimamente con Violeta Parra, y quien se denomina a sí mismo su discípulo, un gesto que evidencia lo magnífica que ella era. Soublette en su calidad de filósofo y semiólogo estudia las letras de sus canciones, llevando su análisis al plano de lo divino y lo espiritual. Que el libro termine con su texto no fue incidental, puesto que en él se funden todas las ideas expuestas anteriormente en un propósito mayor, y es que todo lo dicho sobre Violeta apunta a que ella cumple, en la historia de Chile, una misión semejante a la de una profetiza.

El libro en su totalidad constituye un análisis bastante completo de lo que fue una de las mentes más despiertas que se hayan gestado en el territorio chileno, una tarea difícil y muy bien lograda. La publicación nos invita a reflexionar en torno a quien supo adentrarse en el misterio del alma nacional. Su obra artística es única, pero su contenido es excepcional, sólo una mujer como ella, con una actitud de quien no tiene más misión en el mundo que entregar sus creaciones y ponerlas al servicio de todo un pueblo, pudo y puede, con transversal popularidad, entregarnos mensajes de plena sabiduría. Las comparaciones con la naturaleza presentes en su obra y el paisaje de sus canciones nos reflejan las luces y sombras de la geografía chilena y sus conflictos sociales, incitándonos a la actitud crítica, pero nunca dejándonos de recordar las verdades fundamentales.

11 Violeta Parra nos transmite que el arte y su forma no tienen importancia sino se aprecia primero lo humano, siendo la principal fuente de inspiración y razón de su proceso creativo, las personas. Este libro está repleto de enseñanzas, aprendizajes y pronósticos esenciales para el Chile de hoy y las nuevas generaciones, pues el carácter atemporal de Violeta y la universalidad de su mensaje, hacen de ella un símbolo nacional, en quien todos y todas reconocemos la identidad de lo que significa ser chileno y chilena.

\section{NOTAS FINALES}

i. Revista cultural del Departamento de Estudios del Ministerio de las Culturas, las Artes y el Patrimonio. 